\title{
Incidence of congestive cardiomyopathy
}

\author{
ALF TORP \\ M.D. \\ Departments of Internal Medicine and Clinical Physiology, \\ University of Lund, Malmö General Hospital, S-214 01 Malmö, Sweden
}

\begin{abstract}
Summary
In a stable population of 250000 , the diagnosis of congestive cardiomyopathy could be firmly established in fifty-nine cases during a period of 8 years. This gives an incidence of the disease of $3 / 100$ 000/year. If cases disclosed at post-mortem during the same period are included, the frequency of the disease will equal 5/100 000/year.
\end{abstract}

\section{Introduction}

During the last two decades, increasing interest has been directed towards the concept of cardiomyopathies in general. Although the terminology differs, it is generally agreed, that the entity can be divided into several subgroups with different clinical features. Several reviews have elucidated the characteristics of congestive cardiomyopathy (Perloff, 1971; Goodwin and Oakley, 1972), especially concerning the haemodynamic findings, clinical course and therapeutic alternatives (Yu et al., 1964; Burch, Walsh and Ferrans, 1965; Goodwin, 1973). Some articles have especially emphasized follow-up studies (Hamby, 1970; Shugoll et al., 1972; Demakis et al., 1974; Hess et al., 1977). These studies contain a considerable number of well investigated cases, and it can be stated that knowledge about the clinical picture of congestive cardiomyopathy has increased greatly during recent years.

This study is based on cases investigated at Malmö General Hospital. The city of Malmö is located in the south of Sweden, and has a fairly stable population of about 250000 . The city is served by one hospital only, and the post-mortem rate at the department of pathology is about $90 \%$. These two facts together make the conditions for epidemiological studies very favourable.

\section{Material, results and discussion}

The material to be presented is based on patients suspected of having myocardial disease being admitted for evaluation. Since 1970 , when the study started, and until 1977, there have been approximately 500 cases. At the first visit, each case was judged according to available data to determine the need for further investigation. At this stage quite a large number of cases could be excluded, as no significant signs of heart disease were present. In 174 cases, signs of suspected myocardial disease were so pronounced that they were admitted to hospital and investigated completely. The aim of the investigation was to establish firmly the diagnosis in general and that of congestive cardiomyopathy in particular. This disease has been defined as 'heart muscle disease of unknown cause or association' (Oakley, 1972) causing right or left heart failure at rest or during exercise.

The investigation in each case included careful history with special emphasis on drinking habits, occurrence of heart diseases in the family and infectious diseases preceding the signs and symptoms of heart disease. Physical examination, ECG at rest and during exercise, chest X-ray, phonocardiogram, spirometry and routine blood biochemistry were done. For 2 years, further noninvasive studies using external pulse registration and echo-cardiography were included. Each patient underwent right and left heart catheterization at rest and during exercise, as well as endomyocardial biopsy from the right ventricle. The technical procedures were according to routine methods in the author's laboratory, and have been described elsewhere (Torp, 1973, 1978). The radiological evaluation has included contrast injections in the left ventricle, supravalvularly in the aorta and in some cases even the right ventricle or the pulmonary artery. When considered necessary, selective coronary arteriography was performed. The biopsy specimens from the right ventricle were fixed in neutral formalin and glutaraldehyde for light and electron microscopy respectively.

For a more specialized, non-invasive study of the heart performance, a newly developed method was used. Red blood corpuscles from a sample drawn from the patient at the time for the investigation were labelled with ${ }^{99 \mathrm{mTc}}$ (usually $10 \mathrm{mCi}$ ). This labelled sample was then re-injected into the patient via a catheter in the superior vena cava. A gammacamera in $45^{\circ}$ RAO position then registered the first passage of the tracer through the heart. Using 
the counts from a region of interest corresponding to the left ventricle, a time-activity curve from this area can be drawn with an interval between each point of $40 \mathrm{msec}$. From this curve, the ejection fraction of the left ventricle can be calculated with great accuracy. After $10 \mathrm{~min}$, the injected isotope has mixed completely with the rest of the blood volume, and further registrations in $30^{\circ}$ LAO position can permit visualization of the systolic/ diastolic variations of the left ventricle. The further details of this method are to be published (Hansen et al., 1978).

The complete material and its origin is illustrated in Fig. 1. Of the 174 cases investigated completely,

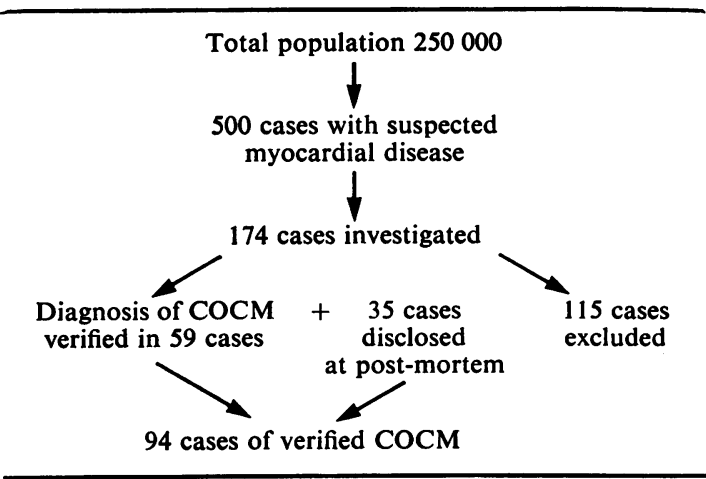

FIG. 1. Congestive cardiomyopathy in Malmö 1970-1977.

twenty were excluded because they lived outside the city. On the other hand, a small number of immigrants were included as they had been inhabitants of the city for many years. A further 95 cases were excluded as they were eventually found to have other forms of heart disease, mainly ischaemic, valvular and also secondary or hypertrophic types of cardiomyopathy. All results were uniformly evaluated and constitute the basis for the diagnosis of congestive cardiomyopathy in fifty-nine of the 174 cases. The sex and age distribution of this clinical material is presented in Table 1, illustrating the expected male predominance. The age given for each patient is that at the time of investigation, regardless of the duration of symptoms before this.

In Table 2, some basic haemodynamic parameters taken at rest are given as well as the heart size estimated from a chest X-ray. A mean pulmonary artery wedge pressure $>12 \mathrm{mmHg}$ at rest and $>16 \mathrm{mmHg}$ during submaximal exercise was considered abnormal and a sign of left heart failure. The heart size was considered normal when $<500$ $\mathrm{ml} / \mathrm{m}^{2}$, the corresponding values for cardiac index and stroke index being $2.81 / \mathrm{min} / \mathrm{m}^{2}$ and $30 \mathrm{ml} /$ beat/ $\mathrm{m}^{2}$ respectively.
TABLE 1. Sex and age distribution

\begin{tabular}{llc}
\hline Total number of investigated cases & & 59 \\
Sex distribution & Women & 11 \\
& Men & 48 \\
Age in years at investigation & Mean & 45 \\
& Range & $15-65$ \\
& s.d. & \pm 14 \\
\hline
\end{tabular}

TABLE 2. Haemodynamic parameters and heart size

\begin{tabular}{lcccc}
\hline & CI & SI & PAW & $\begin{array}{c}\text { heart size } \\
\text { in } \mathrm{ml} / \mathrm{m}^{2}\end{array}$ \\
\hline$N$ & 59 & 59 & 59 & 59 \\
Mean & $3 \cdot 23$ & 41 & 14 & 594 \\
Range & $1 \cdot 80-5 \cdot 65$ & $11-18$ & $1-30$ & $330-980$ \\
\pm s.d. & $1 \cdot 08$ & 18 & 7 & 23 \\
\hline
\end{tabular}

CI, cardiac index; SI, stroke index; PAW, pulmonary artery wedge pressure.

The microscopic evaluation of the myocardial biopsy specimens showed a varying degree of hypertrophy and fibrosis in the majority of cases.

No quantitative angiographic measurements were made. Signs of decreased systolic/diastolic variations were, however, noted, as was the wall thickness of the left ventricle. Even in the absence of quantifica tion, the angiographic findings were in all case abnormal with varying degree of systolic pumpo failure and increase of the thickness of the lefe ventricular wall. Supravalvular contrast injection showed coronary arteries of normal or increased width, usually with a rapid flow of the contrast. Cases with significant coronary sclerosis were excluded, as were those with signs of valvular heart disease or hypertrophic cardiomyopathy.

After the investigation, all the patients were followed-up at regular intervals. During a period of 8 years, nine patients died with their heart disease. Post-mortem of eight of the nine confirmed the clinical diagnosis of congestive cardiomyopathy.

Until now, only a small number of patients have been re-investigated, but the results have fully confirmed the clinical impression of the condition of the patient. Furthermore, the results obtained by the non-invasive methods employing echocardiography and radio-isotope analysis of heart performance at the second investigation showed a very good correlation with the results obtained by conventional heart catheterization and angiography. It is concluded, therefore, that these methods may be used, instead of the more advanced and time-consuming invasive methods, in follow-up studies.

The method mentioned above, labelling of the patient's own red blood corpuscles, gives very valuable information. Variations of the same method have been developed and successfully used by many other workers, for instance Schelbert et al. 
(1976). The great advantage of the method used in this study is the long intravascular half-life of the tracer. This permits serial and exact calculations of different haemodynamic parameters at rest as well as during exercise. The time at disposal, at least $8 \mathrm{hr}$, also permits measurements before and after administration of drugs.

Based on the investigation in each case, it can be stated with acceptable certainty that the diagnosis of congestive cardiomyopathy in the fifty-nine cases is firmly established. All available data, including history, physical examination, haemodynamic, biopsy and angiographic findings uniformly support this diagnosis. Post-mortem of eight cases is a further confirmation.

Fifty-nine clinically diagnosed cases during eight years give an incidence of a little more than seven cases per year, or three cases per 100000 inhabitants per year. In an attempt to get a more complete picture of the occurrence of congestive cardiomyopathy during these eight years, the files of the department of pathology were checked. This revealed thirty-five more cases, which had been unknown before. If these thirty-five cases are included in the material, this will in turn amount to a total of ninety-four cases diagnosed from 1970 to 1977 . This amounts to a frequency of approximately five cases of congestive cardiomyopathy per 100000 inhabitants per year.

The calculation of incidence is impaired with certain difficulties. The discovery of thirty-five unexpected cases diagnosed at post-mortem illustrates this. Another source of error, but probably quite negligible, is persons dying outside the hospital. In these, a thorough post-mortem was not performed. There may have been an unknown number of persons with slight or absent symptoms of heart disease. Such varied factors as these make a retrospective study difficult to evaluate. The figures for incidence and frequency are certainly too low. Fifty of the cases originally admitted for evaluation have not yet been investigated. This is mainly because their signs of heart disease, although present, were not so alarming and complete investigation was indicated. Among these, there must be an unknown number with congestive cardiomyopathy. The introduction of sensitive and reliable non-invasive methods will make a greater number of adequate investi- gations possible, and the extended study will certainly show a higher incidence than $3 / 100000 /$ year.

In conclusion, retrospective studies of incidence are impaired by certain sources of error. Prospective studies, implying increased knowledge of congestive cardiomyopathy and attention towards the occurrence of this disease, may raise the incidence figures to a higher and more realistic level.

\section{Acknowledgments}

This work was supported by a grant from the Swedish National Association for Heart and Chest Diseases. I am greatly indebted to Professor Folke Linell and Professor Nils-Herman Sternby, Department of Pathology, for invaluable help.

\section{References}

Burch, G.E., Walsh, J.J. \& Ferrans, V.J. (1965) Prolonged bed-rest in the treatment of the dilated heart. Circulation, 32, 852.

Demakis, J.G., Proskey, A., Rahimtoola, S.H., Jamil, M., Sutton, G.C., Rosen, K.M., Gunnar, R.M. \& Tobin, J.R. (1974) The natural course of alcoholic cardiomyopathy. Annals of Internal Medicine, 80. 293.

GoodwIN, J.F. (1973) Treatment of the cardiomyopathies. American Journal of Cardiology, 32, 341.

Goodwin, J.F. \& OAKLEY, C.M. (1972) The cardiomyopathies. British Heart Journal, 34, 545.

HAMby, R.I. (1970) Primary myocardial disease. Medicine, 49, 55.

Hansen, F., Dahlström, J. Lilja, B., Mattsson, S., PetTERSSON, C. \& TORP, A. (1978) Measurement of the ejection fraction by ${ }^{99} \mathrm{mTc}$-labelled red blood corpuscles. (To be published.)

Hess, O.M., Turina, J., Goebel, N.H., Grob, P. \& KrayenBÜHL, H.P. (1977) Zur Prognose der kongestiven Kardiomyopathie. Zeitschrift für Kardiologie, 66, 946.

OAKLEY, C.M. (1972) Clinical definitions and classification of cardiomyopathies. Postgraduate Medical Journal, 48, 703.

Perloff, J.K. (1971) The cardiomyopathies - current perspectives. Circulation, 44, 942.

Schelbert, H.R., HenNing, H., Ashburn, W.L., Verba, J.W., Karliner, J.S. \& O'Rourke, R.A. (1976) Serial measurements of left ventricular ejection fraction by radionuclide angiography early and late after myocardial infarction. American Journal of Cardiology, 38, 407.

Shugoll, G.I., Bowen, P., Moore, J.P. \& Lenkin, M.L. (1972) Follow-up observations and prognosis in primary myocardial disease. Archives of Internal Medicine, 129, 67.

TORP, A. (1973) Endomyocardial biopsy. Scandinavian Journal of Thoracic and Cardiovascular Surgery, 7, 253.

TORP, A. (1978) Hemodynamic effects of long-acting glucagon. (To be published.)

Yu, P.N., Cohen, J., Schreiner, B.F. \& Murphy, G.W. (1964) Hemodynamic alterations in primary myocardial disease. Progress in Cardiovascular Diseases, 7, 125. 